(2) Open Access Full Text Article

ORIGINAL RESEARCH

\title{
Implementation of Health Policy on Establishment of Provincial Center of Diseases Control (CDC) in Vietnam
}

This article was published in the following Dove Press journal: Risk Management and Healthcare Policy

\author{
Bui Thi Thu $\mathrm{Ha} \mathbb{D}^{1}$ \\ Tac Pham Van ${ }^{2}$ \\ Tolib Mirzoev (D) $^{3}$ \\ 'Hanoi University of Public Health, \\ Hanoi, Vietnam; ${ }^{2}$ Department of \\ Manpower, Ministry of Health, Hanoi, \\ Vietnam; ${ }^{3}$ Nuffield Centre for \\ International Health and Development, \\ University of Leeds, Leeds, UK
}

Purpose: There is increasing interest in the understanding of key influences over successful implementation of health policies within ever-changing contexts of national health systems. The epidemiological transition in Vietnam, combined with an urgent need for improving efficiency of the national health system under the government's administrative reforms, form important facilitators of restructuring the public health system. This paper explored the implementation processes of policy on establishment of the Centers for Diseases Control (CDC) in Vietnam during 2016-2019.

Methods: The study employed a cross-sectional and mixed methods design. Staff surveys were collected at 55 out of 63 provinces and in-depth interviews, focus groups were conducted in three purposefully selected provinces. Quantitative data were analysed using descriptive statistics and qualitative data were analyzed thematically. The innovation implementation framework guided the study.

Results: After 3 years of introduction, $82.5 \%$ of provinces had established the CDCs. Implementation of CDC establishment policy was influenced by 1) management support; 2) alignment between policy and practice; 3) values towards CDC,; and 4) implementation climate. Other external key influencers included political, social, and cultural factors.

Conclusion: Our study provides a framework and evidence to guide future inquiry into the factors that affect the relationship between policy implementation and other contextual factors in healthcare organizations.

Keywords: Centers for Diseases Control, CDC, public health, innovation implementation framework

\section{Introduction}

There is an increasing interest in understanding key influences over successful implementation of health policies for health sector reforms in low- and middleincome countries. ${ }^{1,3}$ Health sector reform is a complex socio-political and dynamic process, which requires a sustained process of fundamental change in the context of health policy and institutional arrangements. ${ }^{4}$ Most studies typically examine the content of reforms with less attention paid to their processes, ${ }^{4,5}$ and better understanding of how reform policies are implemented is needed to complement and enhance the published evidence on the content of health sector reforms. Such an understanding can inform appropriate strategies for effective implementation of reforms, including addressing the needs of organized stakeholder interest groups.
Correspondence: Bui Thi Thu Ha

Hanoi University of Public Health, No. IA

Duc Thang Road, Duc Thang Ward,

North Tu Liem District, Hanoi, Vietnam

Tel +84-0913363603

Email bth@huph.edu.vn 
Vietnam is a lower middle-income country with a population of over 96 million in $2019^{6}$ and GDP per capita of $\$ 2587$ in $2018 .^{7}$ The population's health status has significantly improved, with life expectancy increasing from 50 years in the 1950 s to 75.37 years in $2019 .{ }^{8}$ Since 1986 , rapid health sector reforms have aimed to improve functioning and performance of the national health system and ultimately the health status of the population. ${ }^{9}$

Along with economic growth, the disease patterns in contemporary Vietnam are shifting from infectious diseases to non-communicable diseases (NCD) and traffic-related injuries. However, the outbreaks of emerging and re-emerging diseases such as severe acute respiratory syndrome (SARS) and Avian Influenza in human (H5N1, H1N1), dengue fever, measles, malaria, and tuberculosis and, more recently, COVID-19 require multisectoral collaboration, surveillance, and comprehensive responses. ${ }^{10,12}$

Public health interventions can be effective in addressing these problems in developing countries. ${ }^{13}$ Different models of public health structures, including those of the United States (US) and China were studied by the Vietnam Ministry of Health. ${ }^{14,15}$

The Centers for Diseases Control and Prevention (CDC) in the US was established in 1942 and has become the premier public health agency in the world. ${ }^{16,18} \mathrm{CDCs}$ are often working with national Ministries of Health to strengthen epidemiological, laboratory, and program implementation capacity. ${ }^{18,20}$ China adopted the US CDC model by consolidating seven institutions of preventive medicine network into a single agency, Shanghai CDC, in 1998. This was considered a model program, which later expanded to the whole country ${ }^{21}$ and has been successfully addressing the burden of diseases over the years. ${ }^{22}$

The CDC started working with the Government of Vietnam since 1998 to build an effective and sustainable public health system. The CDC provided funding and technical support to strengthen the infrastructure and capacity of national health systems in different areas including HIV, Tuberculosis, and Influenza, laboratory services, surveillance, and workforce capacity to respond to disease outbreaks. ${ }^{23}$

The health system in Vietnam comprises four administrative levels: central, provincial, district, and commune. ${ }^{24}$ At each level, the organizational structure is divided into curative care, preventive medicine, and other services. While curative care services are structured vertically through the hospital system, the preventive medicine was fragmented. $^{24,25}$ The central level is composed of three agencies at the Ministry of Health which are responsible for different public health programs: the General Department of Preventive Medicine, Admission for HIV/ AIDS control and prevention, and Health Environmental Management Agency. The provincial level consists of different centers responsible for various public health programs such as HIV/AIDS prevention, reproductive health, preventive medicine, center of information, education, and communication (IEC), food safety, and other preventive medicine facilities. ${ }^{26,27}$ Despite the achievement in prevention and control of diseases, including vaccine development, the network is facing high administrative expenditure, low incentives and shortages of qualified workforce, poor infrastructure, and limited funding. ${ }^{27,31}$

Acknowledging the problem, the Ministry of Health $(\mathrm{MOH})$ plans to reform the preventive medicine network by gradually merging provincial centers in charge of preventive medicine into provincial Centers for Diseases Control (CDC) by January $2021^{29,30}$ and merging three centers at $\mathrm{MOH}$ by $2025 .^{31}$ In 2015, the Ministry of Internal Affairs (MIA) and Ministry of Health (MOH) introduced a policy on consolidating the existing preventive medicine agencies at provincial level into a single agency, ie, provincial Center for Diseases Control (CDC). ${ }^{32}$ In 2017, the MOH released a policy on provincial CDC establishment (Circular No. 26/2017/BYT) with detailed functions, tasks, structure, and roadmap of consolidating existing centers of the preventive medicine network into a single CDC agency. ${ }^{33}$ The functions of the CDC combined those of different individual centers. The roadmap allowed the completion of provincial CDC establishment before January 2021 and the transition was to be taken gradually as appropriate to the local context. After 3 years of implementation, most provinces established the $\mathrm{CDC}$, however some provinces have not yet initiated the process.

This study aims to: 1) Document the progress of initial implementation of the health policy on restructuring provincial preventive medicine networks during 2015-2019, and 2) Identify and analyze key factors that influence the policy implementation. We believe this study will be of interest and relevance to national and international policymakers and practitioners who are interested and engaged in improving the implementation of national health policies; academics who are interested in improving the understanding of policy implementation in different contexts; and funders who are interested in ensuring value for money from their investments in specific policy priorities. 


\section{Theory: An Implementation Science Perspective}

Several theories and frameworks help understand the policy implementation. The well-cited Policy Triangle helps disentangle between four inter-related aspects in health policy analysis: context, contents, processes, and actors. ${ }^{34}$ The Punctuated Equilibrium helps understand periods of relative inactivity (equilibrium) interrupted with outbursts of activity (punctuations) throughout policy processes. ${ }^{35}$ The three-streams theory of agenda-setting helps understand the importance of politics, policies, and the nature of issues that determine the emergence of issues on the government's policy agenda. ${ }^{36}$ Finally, theory of street-level bureaucracy sheds light on the roles of grassroot-level actors in ensuring (or not) policy implementation. ${ }^{37}$ None of these theories suited the questions posed in our study, because these focused on overall policy processes (policy triangle and punctuated equilibrium), policy stages other than implementation (three-streams of agenda-setting), or only on specific factors which affect implementation (street-level bureaucracy). Instead, we grounded our inquiry in the Implementation Science, which is defined as the scientific study of methods to promote the systematic uptake of research findings and other evidence based practice into routine practice to improve the quality and effectiveness of health services and care. ${ }^{38}$ Implementation theories help identify the organizational factors and underlying relationships that are hypothesized to influence effective implementation. Innovation implementation in a healthcare setting refers to the implementation of anything new to the organization, be it an evidence-based practice, policy, or technology. ${ }^{39}$ Adoption of innovations in healthcare has been widely accepted as a complex, organizational process that is much more humanistic than mechanistic. ${ }^{40}$ The review of innovation implementation in the context of healthcare setting, identified as the "Innovation Implementation Framework," originally developed by Klein et al in 1996 and refined by Helfrich et al in 2007, was a popular theoretical framework used to explain factors driving innovation implementation success, particularly in works that sought it retrospectively. ${ }^{39,41}$

We conceptualize the implementation of policy on provincial CDC establishment as implementation of a complex innovation that required collective, coordinated behavior change by many organizational members. ${ }^{42}$ By definition, the establishment of provincial CDCs required organizations at different levels (provincial authorities, provincial department of health, centers of preventive medicine network) to develop and implement innovative practices across multiple functions (administrative and technical activities). Building on the innovation adoption literature, we adopted the Innovation Implementation Framework developed by Klein and colleagues ${ }^{42,43}$ and Helfrich et al, ${ }^{44}$ and which has been increasingly applied to implementation of innovations within healthcare organization. ${ }^{39,41,44,51}$

According to the original framework, implementation effectiveness is defined as the consistency and quality of the targeted organizational members' use of innovation and comprises: a) fit between the innovation and the user's values and b) implementation climate. Implementation climate refers to organizational members' shared perceptions that innovation implementation is considered as an organizational priority and is therefore promoted, supported, and rewarded. ${ }^{43}$ The implementation climate is shaped by an organization's management support, resource availability, and implementation policy and practice. Innovation values fit affects the implementation climate and the role of innovation champions is evident in the healthcare setting. ${ }^{44}$

Figure 1 presents a conceptual framework for this study. It highlights the factors that influence effective policy implementation which lead to examining the implementation of a reforming provincial network of preventive medicine later in this paper. The implementation of policies is directly affected by availability of resources and commensurate management support. In turn, it informs the organizational climate determined by a combination of values within implementing organization and alignment of those values with the policy agenda. All of this operates within a complex socio-economic and cultural contextual environment and shapes the effectiveness of policy implementation.

\section{Methods \\ Study Design}

A cross-sectional study design applying mixed methods of data collection was adopted. This method is appropriate to provide in-depth analysis of organizational context and is well suited for studying implementation of innovations. ${ }^{52}$ Data was collected using quantitative (staff survey) and qualitative (in-depth interviews, focus group discussions, and document review) methods which we detail later.

\section{Study Setting}

The study sites included the national level and provincial level. While a quantitative survey was administered in all 


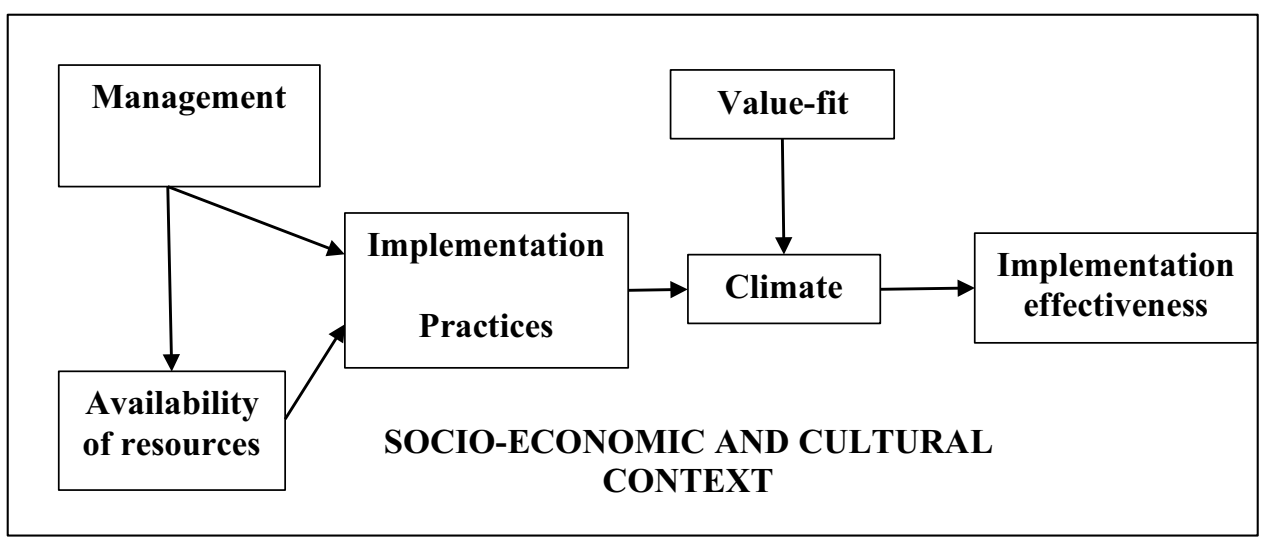

Figure I Conceptual framework for understanding policy implementation (adapted from Klein and colleagues and Helfrich et al).

provinces, three provinces were purposefully selected for indepth assessment using qualitative interviews and focus groups, which represented different stages of CDC establishment (no CDC, with CDC, amended CDC policy) and also three geographical regions of Vietnam and included: Lao Cai (North, with CDC amendment); Dak Nong (Central, recently set up CDC), and Vung Tau (South, no CDC).

\section{Quantitative Methods}

A staff survey was conducted to understand experiences of different provinces in implementing the CDC policy. The self-administered questionnaire was sent out to all 63 provinces in April 2019. The questionnaire covered: current status of CDC, capacity, and context before and after the CDCs establishment (human resources, infrastructure, equipment, finance, information, and management) and problems encountered during the implementation. A total of 55 provinces returned the completed questionnaires, giving the response rate of $87 \%$ (Table 1). The subsequently obtained report from the $\mathrm{MOH}$ confirmed that 6/ 8 provinces that did not complete the questionnaires had CDC already set up. ${ }^{31}$

\section{Qualitative Data Collection}

In-depth interviews (IDIs) and focus group discussions (FGDs) were conducted with key stakeholders at the national and provincial levels to understand views, perceptions, and experiences of individual stakeholders. The participant details are shown in Table 2. Two experienced public health researchers conducted the IDIs or FGDs using the question guides structured around the components of the conceptual framework (Figure 1). The

Table I Characteristics of Provinces in the Survey

\begin{tabular}{|l|l|l|}
\hline Characteristics of Provinces & Frequency & Percentages \\
\hline Status of CDC establishment & $\mathrm{n}=55$ & 100 \\
- Established & 46 & 84.0 \\
- In progress & 9 & \\
- Approved proposal for CDC establishment & 2 & 4.0 \\
- No approval of proposal on CDC establishment & 5 & 9.0 \\
- Developing proposal on CDC establishment & 2 & 4.0 \\
\hline $\begin{array}{l}\text { Human resource } \\
\text { - Decreasing technical staff }\end{array}$ & $\mathrm{n}=46$ & \\
- Decreasing administrative staff & 30 & 66,7 \\
\hline $\begin{array}{l}\text { Facilities } \\
\text { - Having brand new offices }\end{array}$ & 34 & 75,5 \\
\hline Utilization of equipment & $\mathrm{n}=47$ & \\
- Similar as before merging & 4 & 8,5 \\
- Lower & 43 & 91,5 \\
\hline
\end{tabular}


Table 2 IDI and FGD Participants

\begin{tabular}{|c|c|c|c|c|}
\hline Non & Participants & IDI & FGD & $\begin{array}{l}\text { Members } \\
\text { of FGDs }\end{array}$ \\
\hline I & $\begin{array}{l}\text { National level-MOH } \\
\text { Dept of Manpower \& Dept of } \\
\text { Preventive Medicine }\end{array}$ & 3 & & \\
\hline II & $\begin{array}{l}\text { Local provinces } \\
\text { Leaders of } 3 \text { provincial health } \\
\text { departments and Department } \\
\text { of Internal Affairs } \\
\text { Managers of } 2 \text { provincial health } \\
\text { departments with CDC } \\
\text { CDCs leaders of } 2 \text { provinces } \\
\text { CDCs managers of } 2 \\
\text { provinces } \\
\text { CDCs officers of } 2 \text { provinces } \\
\text { Leaders of } 5 \text { centers in the } \\
\text { province that will set up CDC } \\
\text { Managers of } 5 \text { centers in the } \\
\text { province that will set up CDC } \\
\text { Total }\end{array}$ & $\begin{array}{l}3 \\
2 \\
3\end{array}$ & $\begin{array}{l}3 \\
1 \\
1 \\
5\end{array}$ & $\begin{array}{l}20 \\
5 \\
11 \\
36\end{array}$ \\
\hline
\end{tabular}

information was also collected on the rationale for and current status of CDC establishment, preparations for CDC policy implementation including involvement, and relative roles of different actors, key facilitators, and barriers to the CDC implementation, and overall assessment of functions after the CDCs were introduced. Each IDI or FGD lasted about 60 minutes, and FGDs included between five and 11 participants. IDIs and FGDs were audio-recorded following the informed consent and transcribed for data analysis.

A review of existing documents, including the proposal for CDC establishment, decision for CDC establishment, and relevant reports, MOHs, and provincial CDCs websites was conducted in order to understand the policy environment and document experiences of the first 3 years of implementation of the CDC policy. These were purposefully identified with the aid of a snowballing technique which involved reference and citation tracking.

\section{Data Analysis Quantitative Analysis}

The data was entered using EPI DATA and analyzed using SPSS version 14. Descriptive data analysis was used. We reported the status on CDC establishment against the timelines required by the $\mathrm{MOH}$ policies, characteristics of provinces on facilities, human resources, and equipment.
The perceived values fit by health workers and difficulties faced by institutions that implemented the policy on CDC establishment were also are reported.

\section{Qualitative Analysis}

The IDI and FGD transcripts were coded following the components of the conceptual framework shown in Figure 1, by experienced qualitative researchers. The results were extracted and mapped based on the relevant codes. Data was analyzed in Vietnamese and the codes and report were written in English. Selective illustrative anonymized quotes from Vietnamese transcripts were translated verbatim into English for reporting.

\section{Ethical Approval}

The study received ethics approval from the Hanoi University Institutional Review Board (Approval number 273/2019/YTCC-HD3). All primary data collection was conducted following obtaining of informed consent from each participant and the reporting of results protected the participants' identities.

\section{Results}

\section{Progress of Implementation of Policy on Provincial CDC Establishment}

The timeline for the implementation of the MOH's policy on CDC establishment, informed by the results of the document reviews and the survey, is shown in Figure 2. The policy requires all provinces to establish CDC before January 1, 2021, though the introduction could involve several phases depending on the local contexts. ${ }^{33}$ Before the specific function and tasks of provincial CDC were promulgated by the MOH (in Circular No. 26/2017/BYT), five provinces had already set up the CDC by merging the centers of preventive medicine network. ${ }^{31}$

The government regulations on establishment of a new CDC from existing centers included the following three steps to make the CDCs operational: 1) Development of a proposal for CDC establishment inthe province under the leadership of PDH; 2) Review by relevant provincial departments such as the Department of Justice, Department of Finance, or Department of Internal Affairs; 3) Submission to Provincial People's Committee by the Department of Internal Affairs for approval and receiving the Decision for $\mathrm{CDC}$ establishment from the Provincial People's Committee. By July 31, 2019, the MOH roadmap was largely achieved, with 52 out of 63 provinces $(82.5 \%)$ with established CDCs, two provinces 


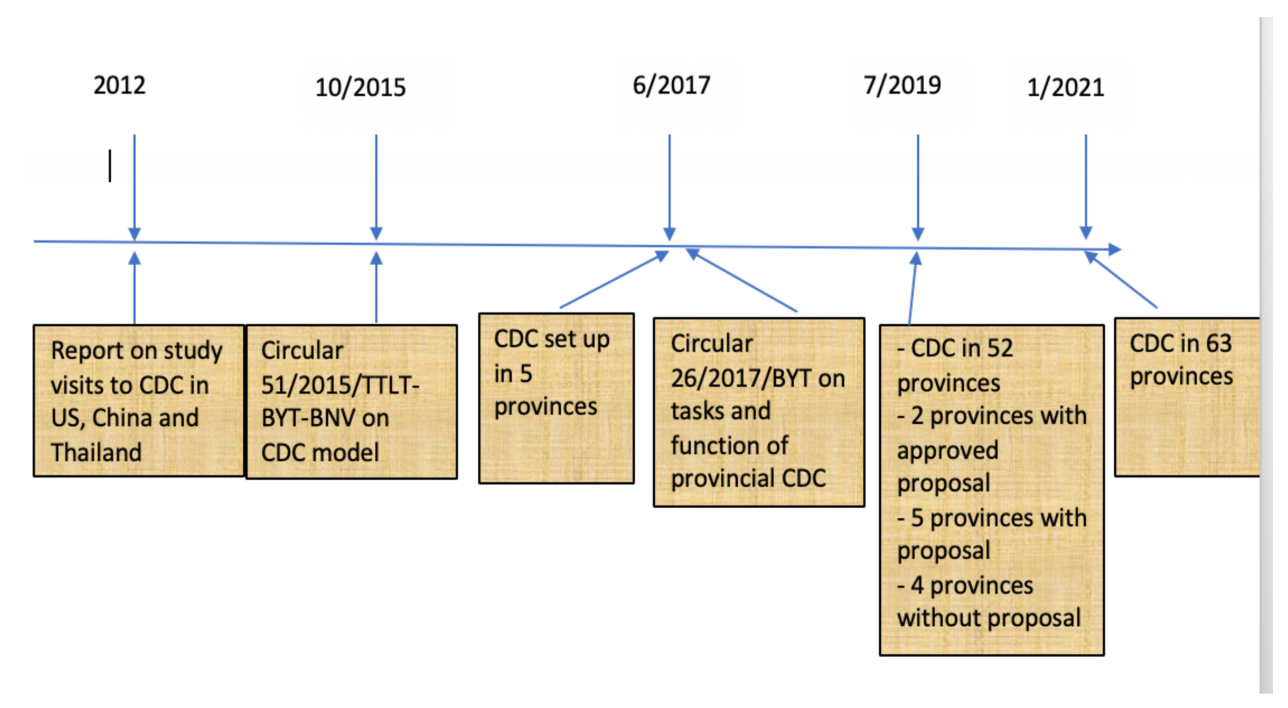

Figure 2 Timelines of CDC establishment in Vietnam.

with approved proposals on CDC establishment by Provincial People's Committees, five provinces with proposals, and only four provinces being without proposals (Table 1).

Only four CDCs were provided with new offices and the rest were located in the same offices, which were spread around respective cities. About two-thirds of provinces reported a reduction of technical and administrative personnel (66-75\%). However, most CDCs utilized equipment as the same pattern before merging (91.3\%) (Table 2).

\section{Factors Which Facilitated the Policy Implementation Management Support}

Management support involved coordinated organizational communication from provincial health authorities on the rationale for establishing the $\mathrm{CDC}$ from existing preventive medicine agencies. ${ }^{42,44}$

Qualitative results showed involvement of different stakeholders in providing such support and highlighted different communication channels used to facilitate the implementation of policy on CDC establishment through multiple rounds of consultation (see Box 1).

Following coordinated communication, proposals on CDC establishment were eventually agreed among stakeholders within each province for implementation. From the study visits and information from provinces, we identified two key lessons: a) the establishment should be at the beginning of the year to avoid difficulties with financial procedures, and b) a transitional period should be followed in the proposal for completion of activities in each center before merging. Communication challenges, such as limitation and variation in communication channels, were recognized as barriers to successful communication. In some provinces or centers, communication reached only the leaders and did not cover all staff, with many being unaware of the CDC functions for some time.

"The implementation was known by leaders and managers. The staff did not know, they did not read the policy on CDC establishment, Circular 26" (IDI_Province_2.3).

\section{Resource Available to Support the Implementation}

Adequate investments in the infrastructure and operational procedures are important to ensure the policy implementation. ${ }^{42,44}$ Most provinces remained working in the same offices and they mentioned difficulties working across different offices such as organizing meetings, obtaining signatures, and approvals from managers who were based in other locations. Losing the loyal clients of reproductive health centers was also a concern for staff when merging into CDCs meant they had to move their offices.

I said, facilities and offices, in the past, centers had their own offices and these were spread around the city. Now merging into one $\mathrm{CDC}$, the offices still there. The problem is with management, coordination with different offices. This will be difficult when having meetings, not focused. (IDI_MOH_03) 


\section{Implementation Policies and Practices}

Implementation policies and practices were used to establish the CDC at the provincial level. ${ }^{42,44}$ These included standardizing procedures and approaches to ensure the availability of skills and incentives to facilitate the set up of CDCs.

Across the provinces, standardized procedures on CDC establishment were important factors to ensure the implementation success. The procedures followed the earliermentioned standardized three-step procedure set out by the $\mathrm{MOH}$. The contents of proposals on CDC establishment were different across provinces, reflecting differences in local contexts and cumulative learning experiences of establishing $\mathrm{CDCs}$ at that time:

We learned from province $\mathrm{X}$ and province $\mathrm{Y}$, based on these experiences, we developed our CDC. We exchanged the experiences, functions, tasks, structures with departments. Each province developed own model, no similarity between provinces. This could be flexibility, fit to the local context of province. (IDI_Province 2.2)

Two major challenges to ensure skills and incentives or overcome obstacles were reported during implementation (Table 2). The surplus of administrative personnel was the most frequently reported (71.8\%). Before merging into $\mathrm{CDC}$, each center had its own drivers, accountants, and administrative officers. After merging, these posts were significantly reduced. Each province had its own solution, such as termination of contracts, early retirements, or staff rotation to other posts or institutions. In addition, some qualified technical staff left due to the low salary in the new CDCs (34\%). Those who stayed were redeployed to similar positions where possible.

Both qualitative and quantitative results showed that in some cases, the provinces chose not to include the Center of International Health Quarantine or Center of Reproductive Health in the first phase of CDC establishment. This was because they were autonomous and had higher incomes, and merging these would have reduced staff incomes.

In some cases, the position of the director affected the phased nature of the CDC establishment process. The first phase did not include the centers where the directors were going to retire in the next few years. Consolidating these centers into the CDC would have meant that not all these people would be promoted as directors, which was perceived as a punishment for their poor performance and even shameful. Recognizing such social norms was important and most leaders of province health departments were cautious to avoid subsequent complaints.

Some provinces, the merging is very difficult, especially the human resource. Some provinces are dealing with this $\mathrm{OK}$, some are not. They wanted to have a roadmap so the director of centers that will be retired soon, they wanted to stay there until retirement as director, they do not want to change this. Some were directors, now merging CDC they became only vice directors, the enthusiasm is lower. (IDI_MOH_3)

Some provinces did not promote new leaders since the issuance of MOH policy on CDC establishment in 2017. This strategy allowed adequate time for retirements of current leaders before merging centers into the CDCs.

\section{Implementation Climate}

The implementation climate comprised the health workers' shared perceptions of priority on the establishment of CDC in the province. ${ }^{42,44}$ Evidence of the urgent need for having CDCs in Vietnam from both literature and qualitative results consistently highlighted three reasons. First, the disease pattern shifted from infectious diseases to noncommunicable diseases (NCDs), ${ }^{10,11}$ which required multi-sectoral collaboration to ensure comprehensive surveillance and responses.

The second reason was to avoid the fragmentation in the preventive medicine network. The provincial centers of the preventive medicine network were established based on the etiology of individual diseases or their clusters such as HIV/AIDS or malaria. Later, these adapted independently to changes in science, technology, and funding of vertical programs, which resulted in overlapping and sometimes conflicting missions and mandates. Many centers had similar functions and tasks, which meant increased administrative expenditure and decreased effectiveness of health services. In the past, one vertical program such as nutrition was allocated to different agencies with ineffective coordination among agencies.

Now, the reproductive health centers moved to CDC, this is better in the area of maternal and child health. Before, the nutrition program is operated by Center of Preventive Medicine and Reproductive Hhealth Ccenter. Center of Preventive Mmedicine is responsible for some activities such as micronutrient day, breastfeeding day, and 30 cluster survey. Reproductive Hhealth Center is responsible for other activities such as prevention of malnutrition. Sometimes, the activities should be collaborative, but leaders of these 
agencies are not getting along and it is quite difficult to work out the joint activities. Moreover, the district center should follow the guidance of these two centers in provincial level, which was quite complicated to implement one program with two bosses. (IDI_Province_2.4)

In each province, there were up to nine centers of preventive medicine in the network. The survey participants felt that consolidation of these centers into a single $\mathrm{CDC}$ reduced the number of organizations and saved costs of staff (drivers, accountant, administrative officers) and office maintenance, which formed core efficiency savings (Table 3). These findings were also confirmed by the qualitative research.

Firstly, merging these centers will utilize the human resources of centers, avoid the surplus of workforce in different agencies and having no work, utilize the technical staff. Secondly, reduce the administrative costs, pooling the medical equipment, increasing efficiency of these equipment, do not need to purchase lots of materials, maintenance costs, very expensive. Also, the salaries for drivers, guards, administrative staff, saving costs for technical staff, responding to burden of diseases, that $\mathrm{CDC}$ is emerged. (IDI_MOH_2)

The third reason was the strong commitment to comply with Party Resolution. The results show that 40/42 provinces (95.2\%) expressed as an obligation to comply with the Central Communist Party's Resolution No. 39 on reducing the number of working posts in all governmental agencies by $10 \%$ in 2020 and the Political Bureau Resolution No. 19 on reforming structures, management, and improving quality and efficiency of government agencies (Table 3). Qualitative results also confirmed this, as exemplified in the quote below:

First, this is the awareness to comply with Party resolution. The leaders of province were aware of this, leaders of

Table 3 Factors Influencing the CDC Establishment in Provinces

\begin{tabular}{|c|c|c|c|}
\hline No & $\begin{array}{l}\text { Factors Influencing CDC } \\
\text { Establishment }\end{array}$ & $\mathbf{n}$ & Percentages \\
\hline I & $\begin{array}{l}\text { Perceived values } \\
\text { Compliance with Party resolution on } \\
\text { improving efficiency } \\
\text { Improving efficiency on utilization of } \\
\text { resources }\end{array}$ & $\begin{array}{l}42 \\
39 \\
30\end{array}$ & $\begin{array}{l}92.9 \\
71.4\end{array}$ \\
\hline II & $\begin{array}{l}\text { Difficulties encountered } \\
\text { Surplus of administrative personnel } \\
\text { Difficulties in retaining qualified } \\
\text { technical staff }\end{array}$ & $\begin{array}{l}39 \\
28 \\
16\end{array}$ & $\begin{array}{l}71.8 \\
41.0\end{array}$ \\
\hline
\end{tabular}

Internal Affairs sector and Health sector were aware of merging these centers, all public agencies, should comply with Party's Directives, Resolution. We all agreed with this direction and we issued the guidance to the lower level to implement. We made the decision and direction. (IDI_Province 1.5)

\section{Values Fit Towards CDC}

In this paper, we interpreted values fit as perceptions of health staff from the preventive medicine agencies towards international best practice of US CDC. We found consistent evidence of values fit towards CDC by health workers in results from both quantitative and qualitative methods. The US CDC model was positioned as the best practice for a preventive medicine network in Vietnam. ${ }^{16}$ For over 20 years it provided significant support to thepreventive medicine network on issues such as HIV/AIDS prevention, emergency response, and laboratory work for emerging diseases. $^{23}$ Therefore, the name of CDC was easily accepted by all relevant ministries and key participants when the first policy on CDC establishment was developed in 2015. The Ministry of Internal Affairs had no comments on using the English name as CDC. Furthermore, some participants stated that Vietnam was late in applying a CDC model compared to other neighboring countries, which indicated gaps between the current CDCs function and core public health functions, especially those related to surveillance and health informatic analysis.

Basically, CDC here is followed the US CDC model. However, this is not exactly the same. In the functions, 3 functions and 14 departments are quite similar to CDC model, but not all.

Overall, PDH was responsible for CDC implementation. The Department of Internal Affairs, which coordinated the development process, was mainly responsible for the human resources of CDC. The Department of Finance was responsible for auditing existing facilities and equipment, planning how many facilities would be utilized, and how to deal with unused facilities and equipment. Across some provinces, no clear champion was reported during implementation.

\section{Discussion}

Initial Implementation of Policy on Provincial CDC Establishment

Policy implementation typically comprises stages of exploration and adoption, program installation, initial implementation, 
full operation, innovation, and sustainability. ${ }^{53}$ Our findings illustrate the complexity and gradual nature of the initial implementations of policy on establishment of provincial CDCs. The data supports the original Innovation Implementation Framework, ${ }^{42,44}$ specifically the importance of management support (coordinated organizational communication on the rationales and priority to establish CDC); implementation policies and practices (Procedures to set up CDC and proposal for CDC operation); implementation climate (responding to changing disease patterns, avoiding fragmentation, compliance to Party Resolution); and values fit (best practice of international model). The findings are also consistent with other studies ${ }^{39,41,44,51}$ and also show that different elements of the framework are clearly inter-related. For example, values fit by the staff from the preventive medicine centers determine the implementation climate at the province level and together with management support from the $\mathrm{MOH}$ and province health department contribute to the effectiveness and speed of implementation of the $\mathrm{MOH}$ policy of an establishment of a provincial CDC network. This framework is therefore appropriate for evaluating complex innovations that require coordinated, collective actions and behavior change by multiple stakeholders. Using this theory also helped us to deepen analysis of ways of strengthening implementation practices.

The implementation climate is identified as a critical component of this framework, which mediates the relationship between policy and practice and implementation effectiveness. $^{42,44}$ In our study, if health staff perceived the procedures of CDC establishment and proposal as appropriate, the implementation could be further accelerated. Therefore, in order to improve the implementation effectiveness, the leaders should ensure open dissemination and communication, to acquire and consider staff views and develop the $\mathrm{CDC}$ proposal that was most appropriate to the needs and expectations of stakeholders on the ground. ${ }^{48}$

In our study, we did not find strong findings in support of resource availability and policy champions, which was in contrast with our initial expectations. ${ }^{42,44}$ In the newly established CDCs, most tasks and functions comprised those of existing preventive medicine agencies, therefore, the existing resources were deemed sufficient to fulfil the tasks of CDC. This could be the reason to explain why resources did not strongly feature in our data as being the key facilitators of the policy implementation within the provinces. Moreover, there were rare opportunities for champions to emerge, given the existing standardized procedures for set up of CDCs and strong leadership commitment to comply with Party Resolution.

We found varying applications of the roadmap for CDC establishment among provinces, for example in terms of agencies to be merged in the first phase. From an implementation sciences perspective, it could be seen as a result of social, political, and organizational contexts ${ }^{53}$ which shape health sector reforms. ${ }^{1,3}$ This is associated with greater flexibility for provinces in relation to compliance with the roadmap within a substantial decision space by the province leaders. ${ }^{54}$ During the reform, the fear of change and complexity of new work can be perceived as barriers for innovation implementation. ${ }^{53}$ This was also our finding, consistently echoing other studies where the local policymakers often have been responsive to local cultural contexts. ${ }^{51,54}$ Consideration of key contextual opportunities and challenges at different levels is an important attribute of successful policy implementation.

Although the framework has been discussed within healthcare organizations before, previous studies were predominantly qualitative in their nature. ${ }^{48}$ Some studies operationalized the framework with a quantitative approach and measures at an individual level instead of aggregate understanding of organizations as a whole. The latter constitutes a useful approach for evaluating implementation effectiveness of CDC after January 2021. The effectiveness could be explored quantitatively on issues such as the roles of science and scientific evidence in public health, health communication on healthy lifestyle, etc. ${ }^{55,56}$

Going forward, effective implementation requires a combination of sufficient funding and human resources; improved physical plant and information systems; effective program implementation and regulatory capacity; and, most importantly, political will at the highest level of government. $^{13}$

\section{Limitations}

The study provinces for qualitative inquiry were purposively sampled for practical and resource reasons. We believe this sample provided insights into what was happening across Vietnam on CDC establishment. However, there is considerable variability in the implementation of the reforms, so results may not be fully generalizable to all provinces. The study did not aim to independently assess outcomes of the implementation of the CDC policy, since most were recently established and there has not been enough time for quality of services to change. Instead, we focused on examining 
policy implementation as a process, and our findings consistently followed the conceptual framework, which strengthened our conclusions and reiterated the applicability of the framework for understanding policy implementation. Future research can extend this exploratory work into evaluating the implementation outcomes in the longer-term.

\section{Conclusions}

After 3 years of implementation, $82.5 \%$ of provinces achieved the roadmap, aimed to reform the provincial preventive medicine network towards improving performance. The CDC reform should be seen more than as merely merging centers. It must be seen as improving public health sector development in Vietnam. However, to ensure the implementation effectiveness of provincial CDC, sufficient and sustained investment is required.

The "Innovation Implementation Framework" allowed us to analyze the implementation and better inform researchers, policymakers, and individuals about the key factors that increase the likelihood of success of policy implementation. Our findings support the utility of the model for analyzing the implementation of complex innovations. Finally, our study provided a framework and evidence to guide future inquiry into the relationship between key contextual factors and policy implementation.

\section{Acknowledgment}

The authors would like to thank all the participants that agreed to contribute to this research despite their busy schedule.

\section{Author Contributions}

All authors contributed to data analysis, drafting or revising the article, gave final approval of the version to be published, and agree to be accountable for all aspects of the work.

\section{Funding}

No external funding was received for this study and internal resources from Hanoi University of Public Health were utilized for data collection and analysis alongside the time donated by all co-authors.

\section{Disclosure}

All authors declare no conflicts of interest in this paper.

\section{References}

1. Bennett S, Mahmood SS, Edward A, et al. Strengthening scaling up through learning from implementation: comparing experiences from Afghanistan, Bangladesh and Uganda. Health Res Policy Syst. 2017;15(Suppl 2):108. doi:10.1186/s12961-017-0270-0

2. Blas E. The proof of the reform is in the implementation. Int $J$ Health Plann Manage. 2004;19(S3:23):S3-S23. doi:10.1002/hpm.781

3. Erasmus E, Orgill M, Schneider H, et al. Mapping the existing body of health policy implementation research in lower income settings: what is covered and what are the gaps? Health Policy Plan. 2014;29 (suppl 3):35-50. doi:10.1093/heapol/czu063

4. WHO-SEARO and SEA/HMM/Meet.18/4, HEALTH SECTOR REFORM: Issues and Opportunities; 2000.

5. Gilson L, Raphaely N. The terrain of health policy analysis in low and middle income countries: a review of published literature 19942007. Health Policy Plan. 2008;23(5):294-307. doi:10.1093/heapol/ czn019

6. General Statistics Office of Vietnam. Preliminary Results of Population and Housing Census 2019; 2019.

7. General Statistics Office of Vietnam. Overview of Socio-Economic of Vietnam 2018; 2018.

8. Macrotrends, https://www.macrotrends.net/countries/VNM/vietnam/ life-expectancy.

9. Ministry of Health. For People's Health Protection, Care and Promotion 2016-2020. MOH 5 Year Plan. Strategic Document. Hanoi: Ministry of Health; 2016.

10. Ministry of Health and Health Partnership Group. Joint Annual Health Report (JAHR) 2015: Strengthening Primary Care at the Grassroots Towards Universal Health Coverage. Hanoi; 2016.

11. Nguyen D, Hoang Van M. Guest Editorial: public health in Vietnam: scientific evidence for policy changes and interventions. Glob Health Action. 2013;6:20443.

12. Takashima K, Wada K, Tra TT, et al. A review of Vietnam's healthcare reform through the Direction of Healthcare Activities (DOHA). Environ Health Prev Med. 2017;22(74). doi:10.1186/s12199-0170682-z

13. Frieden TR, Henning KJ. Public health requirements for rapid progress in global health. Glob Public Health. 2009;4(4):323-337. doi:10.1080/17441690903089430

14. Ministry of Health. Report on Field Visit of US CDC Model; 2012.

15. Ministry of Health. Report on Field Visit to China CDC. Hanoi; 2012.

16. Thackery SB, Sencery DJ, Jaffe HW. Centers for Disease Control. Int Encycl Public Health. 2017;1:549-555.

17. Rolle IV, Pearson ML, Nsubuga P. Fifty-Five Years of International Epidemic-Assistance Investigations Conducted by CDC's Disease Detectives. Am J Epidemiol. 2011;174(suppl 11):S97-S112. doi:10.1093/aje/kwr312

18. Bloland P, Simone P, Burkholder B, et al. The Role of Public Health Institutions in Global Health System Strengthening Efforts: the US CDC's Perspective. PLoS Med. 2012;9(4):e1001199. doi:10.1371/ journal.pmed.1001199

19. Schuchat A, Tappero J, Blandford J. Global health and the US Centers for Disease Control and Prevention. Lancet. 2014;348 (9937):98-101. doi:10.1016/S0140-6736(14)60570-5

20. Frieden TR, Kevin M. The CDC's Center for Global Health. Lancet. 2012;379(9820):986-988. doi:10.1016/S0140-6736(12)60370-5

21. Peng J, Zhang SN, Lu W, et al. Public Health in China: the Shanghai CDC Perspective. Am J Public Health. 2003;93(12):1991-1993. doi:10.2105/AJPH.93.12.1991

22. Hipgrave D. Communicable disease control in China: from Mao to now. J Glob Health. 2011;1(2):458.

23. Center for Disease Control and Prevention. Global Health - Vietnam; 2020. 
24. Duc Cuong L, Kubo T, Fujino Y, et al. Health Care System in Vietnam: current Situation and Challenges. Asia Paci J Dis Manage. 2010;4(2):23-30. doi:10.7223/apjdm.4.23

25. Thi Hoai Thu N, McDonald F, Witter S, et al. "Three Nooses on Our Head": the influence of district health reforms on maternal health service delivery in Vietnam. Int J Health Policy Manage. 2018;7 (7):593-602. doi:10.15171/ijhpm.2017.134

26. Vietnam Prime Minister office. Decision Number 122 on the National Strategy on Protection, Care and Improvement for Vietnamese's People in the Period 2011-2020, Vision to 2030. Vietnam Prime Minister office; 2013.

27. Vietnam Ministry of Health. Decision 1624/QD-BYT 2018 Program of Action of the Ministry of Health Implementing Resolution 20-NQ/ TW 2017 on Protection, Care and Improvement of People's Health in the New Situation. Vietnam Ministry of health: Hanoi; 2018. Available at: https://luatvietnam.vn/y-te/quyet-dinh-1624-qd-byt2018-chuong-trinh-hanh-dong-cham-soc-suc-khoe-nhan-dan161200-d1.html\#tomtat.

28. Ministry of Health and Health Partnership Group. Joint Annual Health Review 2010: Vietnam's Health System on the Threshold of the Five Year Plan 2011-2015. Hanoi: Medical Publishing House; 2011

29. Ministry of Health and Health Partnership Group. Joint Annual Health Review 2016: Towards Healthy Aging in Vietnam. Hanoi: Medical Publishing House; 2017.

30. Ministry of Health. National Policy on Preventive Medicine Up to 2020; 2013.

31. Ministry of Health. Report on Implementation of Resolution No18 and No19 of Central Party; 2018.

32. Ministry of Internal Affairs and Ministry of Health. Inter-Ministetrial Circular: Instruction on Function, Tasks, Responsibility and Organizational Structure of Provincial Department of Health Under Provincial People Committee. City under Central Government and Dept of Health under District people committee, in 51/2015/TTLTBYT-BNV; 2015.

33. Ministry of Health. Circular on Function, Tasks, Responsibility and Organizational Structure of Center of Disease Control of Province. city of central government in 26/2017/TT-BYT; 2017.

34. Walt G, Gilson L. Reforming the health sector in developing countries: the central role of policy analysis. Health Policy Plan. 1994;9 (4):353-370. doi:10.1093/heapol/9.4.353

35. Baumgartner F, Jones B. Agendas and Instability in American Politics. Chicago, London: University of Chicago Press; 1993.

36. Kingdon JW. Agendas, Alternatives, and Public Policies. New York: Harper Collins; 1995.

37. Lipsky M. Street-Level Bureaucracy: Dilemmas of the Individual in Public Services. New York: Russel Sage Foundation; 1980.

38. Eccles MP, BS. M. Welcome to implementation science. Implement Sci. 2006;1(1). doi:10.1186/1748-5908-1-1

39. Rangachari P. Innovation implementation in the context of hospital QI: lessons learned and strategies for success. Innovation Entrepreneurship Health. 2018;5:1-14. doi:10.2147/IEH.S151040

40. Moullin JC, Sabater-Hernández D, Fernandez-Llimos F, et al. A systematic review of implementation frameworks of innovations in healthcare and resulting generic implementation framework. Health Research Policy Sys. 2015;13(16). doi:10.1186/s12961-015-0005-z
41. Skolarus TA, Lehmann T, Tabak RG, et al. Assessing citation networks for dissemination and implementation research frameworks. Implement Sci. 2017;12(97). doi:10.1186/s13012-017-0628-2

42. Katherine J, Sorra JS. Klein and Joann Speer Sorra, The challenge of innovation Implementation. Acad Manage Rev. 1996;21(4):10551080. doi:10.5465/amr.1996.9704071863

43. Klein KJ, Conn AB, Sorra JS. Implementing Computerized Technology: an Organizational Analysis. $J$ Applied Psychol. 2001;86(5):811-824.

44. Helfrich CD, Weiner BJ, McKinney MM, et al. Determinants of Implementation Effectiveness. Adapting a Framework for Complex Innovations. Med Care Res Rev. 2007;64(3):279-303. doi:10.1177/ 1077558707299887

45. Jessie-Lee M, Warner G, Lawrence L, et al. The application of implementation science theories for population health: A critical interpretive synthesis. AIMS Public Health. 2018;5(1):13-30. doi:10.3934/publichealth.2018.1.13

46. McAlearney AS, Garman AN, Song PH, Song PH. Implementing High-Performance Work Practices in Healthcare Organizations: qualitative and Conceptual Evidence. J Healthcare Manage. 2013;58 (6):446-464. doi:10.1097/00115514-201311000-00011

47. Chambers A, Mustard CA, Breslin C, et al. Evaluating the implementation of health and safety innovations under a regulatory context: A collective case study of Ontario's safer needle regulation. Implement Sci. 2013;8(9). doi:10.1186/1748-5908-8-9

48. Jacobs SR, Weiner BJ, Reeve BB, et al. Determining the predictors of innovation implementation in healthcare: a quantitative analysis of implementation effectiveness. Health Service Res. 2015;15(1):6. doi:10.1186/s12913-014-0657-3

49. Woiceshyn J, Blades K, Pendharkar SR. Integrated versus fragmented implementation of complex innovations in acute health care. Health Care Manage Rev. 2017;42(1):76-86. doi:10.1097/HMR.0000 000000000092

50. DiMartino LD, Birken SA, Hanson LC, et al. The influence of formal and informal policies and practices on health care innovation implementation: A mixed-methods analysis. Health Care Manage Rev. 2018;43(3):249-260. doi:10.1097/HMR.0000000000000193

51. Weiner BJ, Belden CM, Bergmire DM, et al. The meaning and measurement of implementation climate. Implement Sci. 2011;6(78). doi:10.1186/1748-5908-6-78

52. Palinkas LA, Aarons GA, Horwitz S, et al. Mixed Method Designs in Implementation Research. Admin Policy Mental Health. 2010;38 (1):44-53. doi:10.1007/s10488-010-0314-z

53. Fixsen DL,NS, Blase KA, Friedman RM, Wallace F. Implementation Research: A Synthesis of the Literature. FMHI Publication \# 231. Vol. Louis De La Parte Florida Mental Health Institute, the National Implementation Research Network. Vol. 2005. Tampa, FL: University of South Florida,; 2005.

54. Le G, Thu Thi Bui H, Mirzoev T, et al. Negotiating Compliance: the Case of Autonomous Hospitals in Vietnam. Dev Policy Rev. 2015;33 (3):373-390. doi:10.1111/dpr.12112

55. Vuong QH. The (ir)rational consideration of the cost of science in transition economies. Nat Human Behav. 2018;2.

56. Quan Hoang V. Sociodemographic Factors Influencing Vietnamese Patient Satis- faction with Healthcare Services and Some Meaningful Empirical Thresholds. Iran J Public Health. 2017;47(1):119-126. 


\section{Publish your work in this journal}

Risk Management and Healthcare Policy is an international, peerreviewed, open access journal focusing on all aspects of public health, policy, and preventative measures to promote good health and improve morbidity and mortality in the population. The journal welcomes submitted papers covering original research, basic science, clinical \& epidemiological studies, reviews and evaluations, guidelines, expert opinion and commentary, case reports and extended reports. The manuscript management system is completely online and includes a very quick and fair peer-review system, which is all easy to use. Visit http://www.dovepress.com/testimonials.php to read real quotes from published authors. 